\title{
Microwave-assisted extraction of phenolic compounds from Moringa oleifera seed as anti- biofouling agents in membrane processes
}

\author{
Ni'matul Izza ${ }^{1}$, Shinta Rosalia Dewi ${ }^{1}$, Ashried Setyanda ${ }^{1}$, Agung Sukoyo ${ }^{2}$, Panggulu \\ Utoro $^{2}$, Dimas Firmanda Al Riza ${ }^{3}$,and Yusuf Wibisono, ${ }^{1,4 *}$ \\ ${ }^{1}$ Bioprocess Engineering, University of Brawijaya, 65145 Malang, Indonesia \\ ${ }^{2}$ Agriculture Engineering, University of Brawijaya, 65145 Malang, Indonesia \\ ${ }^{3}$ Agriculture and Environmental Engineering, Kyoto University, 606-8501 Kyoto, Japan \\ ${ }^{4}$ MILI Water Research Institute, PO Box 301 ML, Malang, Indonesia
}

\begin{abstract}
Moringa seed has known as a coagulant in the water purification process. It is because of the large amount of anti-microbial compounds contained in it. Phenol is one of the most common antimicrobial compounds found in natural materials. The aim of this study was to determine the total phenolic content (TPC) of Moringa seed which was extracted by Microwave-Assisted Extraction (MAE). Moringa seeds were characterized by FTIR and showed that it contained phenol compounds confirmed by specific peak in some areas. Moringa seeds were characterized by FTIR before extracted. Therefore, MAE was performed by variation of solvent ratios $(1: 4,1: 6,1: 8)$ and extraction time (2, 3, $4 \mathrm{~min})$. The highest TPC of $41.78 \mathrm{mg} \mathrm{GAE} / \mathrm{g}$ dw was reached at 1: 8 solvent ratio and 3 -min extraction time.
\end{abstract}

\section{Introduction}

Moringa seed has many benefits both for human health and for other fields. Some of its popular uses are as coagulants and flocculants in water purification processes $(1,2)$. The combination of Moringa seed and aluminum sulfate was reported to decrease turbidity in the purification process, up to $96.8 \%$ (3). In addition, Moringa seed also acted as adsorbents that can reduce heavy metal such as $\mathrm{Cu}, \mathrm{Ni}, \mathrm{Cr}(4)$ and $\mathrm{Pb}(5)$ in water. The seed potential as an antibacterial agent has also been reported (6). Moreover, Moringa seed extract exhibited a high potential as anti-fungal (7). The various benefits of Moringa seed make this plant potentially used as Biofouling Reducer Agent (BFR); a material used to prevent a biological contamination that can interfere with the membrane filtration process $(8,9)$.

Phenol compounds have been known to have antioxidant and antibacterial properties (6). Moringa seed contains high phenol compounds so potentially as natural antioxidants in food products and medicines (10). The uptake of phenol compounds from natural

* Corresponding author: Y_Wibisono@ub.ac.id 
materials (ex: Moringa seed) can be done by extraction process. Some extraction methods have been applied in the collection of phenol compounds from Moringa seeds such as soxhlet extraction (10), supercritical extraction (11), and thermal extraction (12). These methods have not shown optimal results in terms of both the yield and the extraction time.

The most conventional methods, maceration and reflux, are used for the extraction of phenol compounds from natural materials. However, both methods are less efficient because they require a long time and a large amount of solvents. Microwave-Assisted Extraction (MAE) was a novel technology of extraction method which can reduce extraction time and solvent usage, and increase the yield of extractioni (13). In MAE, microwaves heat and evaporate water from cell. As a result, the cell undergoes swelling, stretching and rupturing, thus facilitating the metabolic compound to exit and is extracted by the solvent. The aim of this study was to determine the total phenolic content (TPC) of Moringa seed which was extracted by Microwave-Assisted Extraction (MAE) and further used as BFR.

\section{Experiments}

\subsection{Materials}

Moringa seeds used in this study were obtained in Jombang city, East Java, Indonesia. The analytical grade chemicals such as Gallic acid, Sodium carbonate, Folin-Ciocalteau solution, and ethanol were used to analyze the Total phenolic Content (TPC). Samsung microwave (MG23H3185), Philips blender HR 2106, rotary vacuum evaporator (Heidolph), spectrophotometer UV-Visible (Spectronic Genesys 10 S UV), and Digital Camry type EK5055 and Mettler PM460 were used in this study to conduct the extraction and to analyze the extract.

\subsection{Methods}

\subsubsection{Characterization of Moringa seeds}

Prior to the extract of phenol compounds, Moringa seed was characterized by Fourier Transform Infra-Red (FTIR) to determine qualitatively what compounds contained in it

\subsubsection{Extraction of Moringa seeds}

The sorted Moringa seeds were dried at $60{ }^{\circ} \mathrm{C}$. Then, it cut into smaller pieces and blended. Moringa seeds were extracted by MAE method using various ethanol ratios (1: 4, 1: 6 , and 1:8) and time variations i.e. 2, 3, and 4 minutes. The filtrates were evaporated at temperature of $50{ }^{\circ} \mathrm{C}$ to obtain the concentrated Moringa seed extract. The concentrated extracts of Moringa oleifera were then characterized by using FTIR while their TPCs were analyzed by Folin-Ciocalteau's method.

\subsubsection{Determination of Total Phenolic Content (TPC)}

The determination of TPC was done by Folin-Ciocalteau's method with Gallic acid as standard solution (14). The sample $(0.2 \mathrm{ml})$ was reacted with $0.8 \mathrm{ml}$ sodium carbonate $20 \%$ and $1 \mathrm{ml}$ of Folin-ciocalteau. The sample was allowed to stand for 1 hour, then measured its absorbance at a wavelength of $765 \mathrm{~nm}$. These methods can be repeated to make calibration curve. The total content of phenol was calculated as follows: 


$$
\text { Total content of phenol }(m g / l E A G)=A b s / m+C
$$

where Abs is absorbance (A), $\mathrm{m}$ is the slope of the standard curve of Gallic acid and $\mathrm{C}$ is a constant (intercept).

\section{Results and Discussion}

\subsection{Moringa Seeds Characteristics}

Prior to the extraction of phenol compounds, Moringa seed was first characterized by FTIR. The FTIR spectra (Figure 1) shows that Moringa seed contains phenolic compounds confirmed by the appearance of specific peaks such as peak of $\mathrm{OH}$ phenolic at $3321.96 \mathrm{~cm}^{-}$ ${ }^{1}$, peak of $\mathrm{C}=\mathrm{C}$ alkenes at $1657.50 \mathrm{~cm}^{-1}$, vibration of $\mathrm{C}-\mathrm{OH}$ bending at $1057.68 \mathrm{~cm}^{-1}$, and CO stretching of phenol at $1237.05 \mathrm{~cm}^{-1}$. Due to its phenolic compounds, the Moringa oleifera can be extracted and potentially acts as anti-microbial and anti-fungal. Therefore, it can be used as biofouling reducer agent (BFR) on membranes.

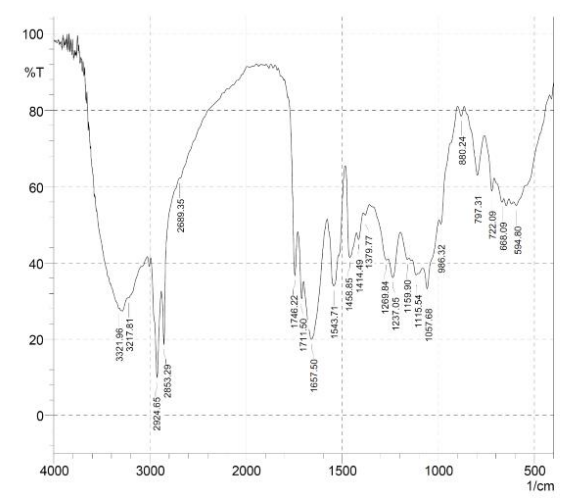

Fig. 1. FTIR spectra of Moringa seed.

Furthermore, Moringa seed was extracted by MAE method using ethanol solvent and ratio of Moringa seed to solvent of 1: 4, 1:6, and 1: 8 at various time (2, 3, and 4 minutes). The extracts are then characterized by FTIR. The FTIR spectra of Moringa seed extract are shown in Figure 2. Figure 2 shows that Moringa seed extract contains phenolic compounds confirmed by the presence of phenol peaks between 3005.65 to $3445.39 \mathrm{~cm}^{-1}$ (-OH groups of phenols); $2924.65 \mathrm{~cm}^{-1}$ (C-H stretching); $1242.63 \mathrm{~cm}^{-1}$ (C-O group of phenol), and peak of $\mathrm{C}=\mathrm{C}$ group at $1711.43 \mathrm{~cm}^{-1}$ and peak of $938.10 \mathrm{~cm}^{-1}(\mathrm{C}-\mathrm{C}$ and $\mathrm{C}=\mathrm{C}$ group of aromatic compounds). 


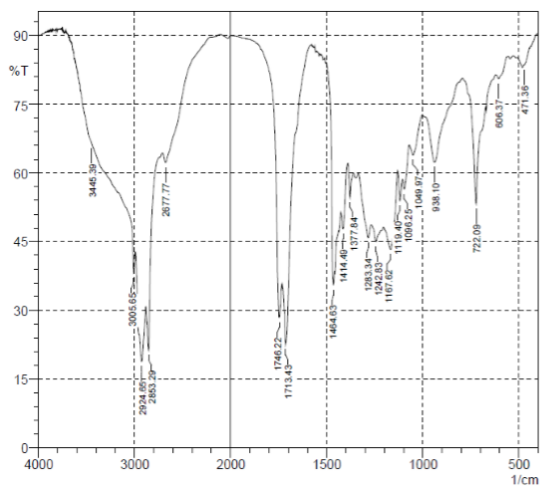

Fig. 2. FTIR spectra of Moringa seed extract.

\subsection{Total Phenolic Content of Moringa Seeds Extract}

The yellow extracts were obtained from Moringa seed extraction process. The extracts were then determined for TPC's content by using Spectrophotometer UV-Visible at $765 \mathrm{~nm}$ of wavelength. The TPC was measured on milligrams of Gallic Acid Equivalents (GAE) per g sample of dry Moringa seed. The TPC of Moringa seeds extract are shown in Figure 3. The TPC of Moringa seed extract ranges from $6.70 \mathrm{mg} \mathrm{GAE} / \mathrm{g} \mathrm{dw}$ to $41.78 \mathrm{mg} \mathrm{GAE} / \mathrm{g} \mathrm{dw}$. The highest TPC of $41.78 \mathrm{mg} \mathrm{GAE} / \mathrm{g} \mathrm{dw}$ was obtained at solvent ratio of 1: 8 (12.5 grams of Moringa seed: $100 \mathrm{ml}$ of ethanol) and 3-minute extraction time.

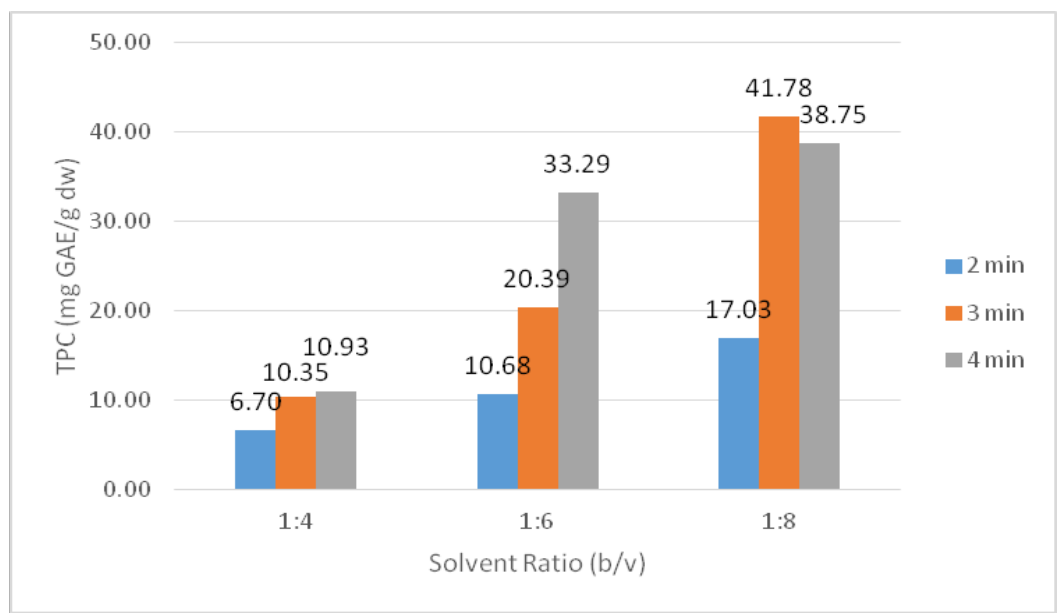

Fig. 3. Total Phenolic Content of Moringa seed extract.

From Figure 3, it can be seen that the longer the extraction time, the higher the total phenol in the extract. This is because the longer extraction time, the more intensive microwave to destruct cell walls, so that the amount of phenol dissolved in ethanol also increases. Moreover, at 1: 8 solvent ratio, the longer extraction time, the smaller total phenol, ie 4 minutes. It was caused by the heat accumulation that occurs during the extraction process using microwaves. It makes phytochemical compounds in the material, including phenol, experiencing enzymatic degradation and oxidation (15). The high amount of solvent causes the heat conductivity of the material become larger, so does the heat 
effect generated by the microwaves. It causes of the destruction of phenol compounds in the extract. Furthermore, Lovrić et al.(16) stated that a long MAE extraction times did not show significant effects on the yield and it was also explained by Fick's second Law of diffusion, where the final equilibrium between the solute and the solvent has been achieved at the short extraction time. Uttara, et al (17) also stated that short extraction time is one of the advantages of MAE because it can decrease the risk of degradation and oxidation of phytochemical compounds in the material and can also reduce the energy consumption during the extraction process.

When viewed from the comparison between the weight of the Moringa seed and the volume of the solvent (Figure 3), it is clearly explained that the more solvent used, the higher the total phenol extracted. This is in accordance with the research conducted by Izza, et al. (18) who also extracted the phenol compounds from Cosmos caudatus by PEF extraction. They obtained the highest yield of total phenol in the treatment with higher solvent ratio, ie the ratio of 1: 8 . It is because the more solvents were used, the more intensive of solvent interaction. Also, the penetration of micro-waves in the material becomes more intensive then the release of phenol compounds becomes more optimal. In addition, the use of high solvent causes the concentration of phenol compounds in the solvent during extraction is lower than the treatment using low one. This causes the mass transfer rate of the phenol compound from the material to the solvent becomes higher. Furthermore, the use of high solvent causes thermal conductivity of the solution will be higher, so the heat effect of the microwaves can optimally aid the process of cell wall destruction and the release of phenol compounds from the material.

Phenolic compounds have an effective antibacterial activity. Phenol will interact with bacterial cells through an absorption process involving hydrogen bonds. The presence of such interactions interferes with the cytoplasmic membrane, inhibits active transport, and proton strength that can cause bacterial cell death. Phenolic compounds will absorb into the cytoplasmic membrane and bind to components in cell membranes such as proteins, nucleic acids, and phospho-lipids which lead to increase membrane permeability and inhibit the development of DNA. As a result the defective cell's components will come out of the cell so that the cells will die $(19,20)$.

\section{Conclusions}

The FTIR spectra shows that moringa seeds were proven to contain anti-microbial phenol compounds. The highest TPC of Moringa seed extract was $41.78 \mathrm{mg}$ GAE / g dw that obtained at 1: 8 solvent ratio and 3-minutes extraction time. These results prove that Moringa seeds are highly potential to be used as BFR.

The author would like to acknowledge Directorate of Research and Community Service, Ministry of Research, Technology and Higher Education for providing funding of this research under the scheme of Penelitian Unggulan Perguruan Tinggi (PUPT) 2017.

\section{References}

1. A. T. A. Baptista et al., Chemical Engineering Journal 276, 166 (2015)

2. F. P. Camacho, V. n. S. o. Sousa, R. n. Bergamasco, M. Ribau Teixeira, Chemical Engineering Journal 313, 226 (2017)

3. J. H. E. S. Freitas et al., Chemosphere 163, 133 (2016) 
4. M. Matouq, N. Jildeh, M. Qtaishat, M. Hindiyeh, M. Q. Al Syouf, Journal of Environmental Chemical Engineering 3, 775 (2015)

5. S. M. A. Basra, Z. Iqbal, R. Khalil ur, R. Hafeez Ur, M. F. Ejaz, Journal of Applied Research and Technology 12, 560 (2014)

6. R. S. Govardhan Singh, P. S. Negi, C. Radha, Journal of Functional Foods 5, 1883 (2013)

7. R. El-mohamedy, A. M Abdallah, Middle East J. Agric. Res 242-249. (2014)

8. Y. Wibisono, F. Ahmad, E. R. Cornelissen, A. J. B. Kemperman, K. Nijmeijer, Desalination and Water Treatment 57, 17625 (2016)

9. Y. Wibisono, Dissertation, Universiteit Twente (2014)

10. F. Ghafar et al., Science Heritage Journal (2017)

11. S. Zullaikah, I. Saputra, G. Prihandini, M. Rachimoellah, IPTEK Journal of Proceedings Series (2015)

12. M. Sulaiman, F. Abd Manan, Analysis of Totalphenolics, Tannins and Flavonoids from Moringa Oleifera Seed Extract, Journal of Chemical and Pharmaceutical Research 132-135 (2015)

13. V. Mandal, Y. Mohan, S. Hemalatha, Pharmacognosy reviews 1, 7 (2007)

14. Y. Liu, S. Wei, M. Liao, Industrial Crops and Products 49, 837 (2013)

15. A. Khoddami, M. A. Wilkes, T. H. Roberts, Molecules 18, 2328 (2013)

16. V. Lovric, P. Putnik, D. B. Kovacevic, M. Jukic, V. Dragovic-Uzelac, Food technology and biotechnology 55, 243 (2017)

17. J. Uttara, W. Leena, U. Mohini, Int J Pharm Bio Sci 1, 330 (2010)

18. N. m. Izza, S. R. Dewi, A. W. Putranto, D. R. Yuneri, M. Y. S. Dachi, Jurnal Teknologi Pertanian 17, 91 (2016)

19. H. Arakawa, M. Maeda, S. Okubo, T. Shimamura, Biological and Pharmaceutical Bulletin 27, 277 (2004)

20. H. Gradisar, P. Pristovsek, A. Plaper, R. Jerala, Journal of Medicinal Chemistry 50, 264 (2007) 